Enhancement of Family-Based Community Resilience during Disasters Caused by Natural Hazards and Massive Civil Emergencies

Jacinto Inbar, $\mathrm{PbD}$

School of Education, Bar Ilan University, Israel

In most communities, the ability to prevent or to cope with disasters and the recuperation of the community depend, among other things, on community resilience. Community resilience can be defined as the capacity to cope with and rebound from massive crises; to continue with current and future community projects, thereby maintaining and enhancing the quality of life. In short, community resilience reflects the on-going growth in the face of adversity. (Inbar, 1994)

Family-based community resilience (FBCR) focuses on family resilience, which can increase essential factors of protection, the capabilities and abilities for prevention, coping and recuperation factors, and rehabilitation. Family resilience is defined "as the capacity to rebound from adversity strengthened and more resourceful. It is an active process of endurance, self-righting, and growth in response to crisis and challenge", (Walsh, 2002).

Professionals in the area of prevention of and coping with disasters have questioned why, in the face of adversity, some communities are more resilient than others. This study focuses on the idea that the main social unit that copes with these adversities is the family. It is the family that transmits and communicates attitudes, beliefs, values, and also coping abilities and skills. This presentation offers a brief review of the FBCR model of community resilience based on family resilience, along with a reflection on the possibilities of implementation in different communities.

Today, there is substantial evidence and experience to show the benefits associated with the implementation of the main ideas of FBCR. It will be shown how to increase potential abilities, capabilities, and skills in preventing, coping with, and rehabilitating communities that suffer from disasters caused by natural hazards and civil emergencies.

Keywords: community; disaster; family-based community resilience; preparedness; resilience

Prebosp Disaster Med

Resilience of the Turkish Jewish Community in the Face of Terrorism

Michael Ettinson $M P H ;{ }^{1}$ Eshet Eyal ${ }^{1}$

Tzipi Hornik-Lurie; ${ }^{2}$ Gil Shenhar ${ }^{3}$

1. Multi Disciplinary Program for Emergency and Disaster Management for Emergency and Disaster Management, Israel

2. Ben-Gurion University of the Negev, Israel

3. Academic Coordinator Program, Israel

Background: In 1986 and 2003, the Jewish community of Istanbul faced two terrorist attacks that have had long-term ramifications. Following the attacks, no psychological intervention or long-term support was provided by the municipality; however the community did provide its own resources. The Jews of Istanbul remain a potential target. Similar incidents in the future could affect catastrophically the fabric of the community.
Methods: This study used a 74- question questionnaire pertaining to the resilience of the community and employed two indicators, "avoidance behavior" and "public fear". Responses $(\mathrm{n}=210)$ were analyzed against "circles of vulnerability" and centered on exposure to the events with a focus on optimism, present fear and anxiety, relationship to community, sense of security, religiosity, and current behavioral patterns associated with everyday life.

Results: The 1986 events still affect resilience, and hint that a previous event does not protect the individual or community from dealing with future trauma. Professions, especially white collar professions, increased the amount of "avoidance behavior" in context with the "circle of vulnerability". In addition, results indicated that higher education translated into lower resilience. Age primarily influenced "public fear", and the age interval of 30-39 years proved least resilient. Gender did not directly or indirectly influence resilience; this was in contrast to current research that shows that gender differences exist in regards to the ability to cope, and that gender is related significantly to the level of stress.

Conclusions: The influence of terrorism does not dissipate over time, and thus, it is necessary to create awareness in communities regarding preparation and response.

Keywords: behavior; community; fear; psychological; resilience; terrorism; vulnerability Prebosp Disaster Med

\section{Should Civilian Staying Power be a Consideration in Deciding to Evacuate a Hospital? \\ Bruria Adini, PbD; $;^{1,2}$ Danny Laor, MD, MHA;, ${ }^{1,2}$ \\ Boaz Lev, MD; ${ }^{1}$ Avi Israeli, MD, $M P H^{1,3}$ \\ 1. Ministry of Health, Israel \\ 2. PRepaRED Research Center, Ben Gurion University of the Negev, Israel \\ 3. School of Public Health, Hebrew University, Israel}

During national emergencies, the Ministry of Health (MOH) is responsible for orchestrating the response of the healthcare system. Over the past three years, the issue of evacuating a hospital was debated twice. The authors are not aware of any research on the effects such an evacuation would have on the staying power of the affected population. Should civilian staying power be a consideration in the MOH's decision to evacuate hospitals?

During the $2^{\text {nd }}$ Lebanon War, the Mizra Psychiatric Hospital suffered a direct hit by a Lebanese missile. Though the damage was limited, the hospital had no structural protection, and therefore, evacuation was undertaken. The civilian population in the region was not evacuated. The $\mathrm{MOH}$ considered the issue of staying power prior to the decision to evacuate the hospital, including the needs of the population, psychological impact of evacuation on the community, consequences for transferring patients to other facilities, and the potential danger to patients and staff.

During the Gaza incursion, a single salvo of missiles was fired at the city of Nahariya, far distant from the conflict zone. The population of the region was not ordered a prolonged stay in shelters. The Nahariya hospital's administration requested a directive from the $\mathrm{MOH}$ to evacuate patients to underground shelters sufficient for approximately two-thirds of the patients. The decision of the MOH was not to evacuate the hospital. 